\title{
Haem oxygenase protects against thrombocytopaenia and malaria-associated lung injury
}

Isaclaudia G. de Azevedo-Quintanilha ${ }^{1 *}$ (D), Isabel M. Medeiros-de-Moraes ${ }^{1}$, André C. Ferreira ${ }^{1,2}$, Patrícia A. Reis ${ }^{1}$, Adriana Vieira-de-Abreu ${ }^{3}$, Robert A. Campbell ${ }^{4}$, Andrew S. Weyrich ${ }^{4}$, Patricia T. Bozza ${ }^{1}$, Guy A. Zimmermann ${ }^{4}$ and Hugo C. Castro-Faria-Neto ${ }^{1}$

\begin{abstract}
Background: Malaria-triggered lung injury can occur in both severe and non-severe cases. Platelets may interact with parasitized erythrocytes, leukocytes and endothelium. These interactions can lead to microvessel obstructions and induce release of inflammatory mediators. Induction of the haem oxygenase enzyme is important in the host's response to free haem and to several other molecules generated by infectious or non-infectious diseases. In addition, an important role for the haem oxygenase- 1 isotype has been demonstrated in experimental cerebral malaria and in clinical cases. Therefore, the present work aims to determine the influence of haem oxygenase in thrombocytopaenia and acute pulmonary injury during infection with Plasmodium berghei strain NK65.
\end{abstract}

Methods: C57BL/6 mice were infected with P. berghei and analysed 7-10 days post-infection. For each experiment, Cobalt Protoporphyrin IX/CoPPIX or saline were administered. Bronchoalveolar lavage fluid was used for total and differential leukocyte count and for protein measurement. Lungs were used for histological analyses or for analysis of cytokines and western blotting. The lung permeability was analysed by Evans blue dye concentration. Platelet-leukocyte aggregate formation was assayed using the flow cytometer.

Results: Plasmodium berghei NK65 infection generated an intense lung injury, with increased levels of inflammatory mediators, oedema, and cell migration into the lung. Plasmodium berghei infection was also accompanied by marked thrombocytopaenia and formation of platelet-leukocyte aggregates in peripheral blood. Treatment with the HO-1 inducer cobalt protoporphyrin IX (COPPIX) modified the inflammatory response but did not affect the evolution of parasitaemia. Animals treated with CoPPIX showed an improvement in lung injury, with decreased inflammatory infiltrate in the lung parenchyma, oedema and reduced thrombocytopaenia.

Conclusion: Data here presented suggest that treatment with COPPIX inducer leads to less severe pulmonary lung injury and thrombocytopaenia during malaria infection, thus increasing animal survival.

Keywords: Acute lung injury, Acute respiratory distress syndrome, Inflammation, Malaria, Platelets, Heme oxygenase 1

*Correspondence: igomesdeazevedo@gmail.com

1 Laboratório de Imunofarmacologia, Instituto Oswaldo Cruz, Fundação Oswaldo Cruz, Rio de Janeiro, RJ, Brazil

Full list of author information is available at the end of the article

\section{Background}

According to the World Health Organization (WHO) malaria remains a major public health problem. In 2018, there were an estimated 220 million cases of malaria in 87 countries, with estimated number of malaria deaths stood at 405,000 [1]. The malaria 
symptomatic triad is formed by the association of fever, chills and headache. The non-specificity of these symptoms leads to a delay in seeking medical attention and to delayed diagnosis and treatment. This scenario is a recipt to serious clinical complications of the disease, such as metabolic acidosis (mainly respiratory distress), malaria associated acute respiratory distress syndrome (MA-ARDS), cerebral malaria (MC) and severe malaria anaemia (SMA) [2]. MA-ARDS, common in infections caused by Plasmodium falciparum and Plasmodium vivax [3]. The most common manifestation of pulmonary malaria is pulmonary oedema, the accumulation of alveolar fluid. In addition, MA-ARDS involves accumulation of monocytes and macrophages in the alveoli and an intravascular inflammatory response in pulmonary microvessels. Pulmonary oedema is triggered by increased permeability of the alveolar-capillary membrane, leading to loss of intravascular fluid, with accumulation of macrophages followed by intravascular inflammatory response. The immune response generated in the lung can also lead to airway obstruction [4-7].

In malaria there is also a marked thrombocytopaenia, which is rarely accompanied by haemorrhage, so it is often not considered as one of the signs of severity; however, a case study of children with falciparum malaria found that thrombocytopaenia has a positive correlation with death [8]. Platelets are discoid-shaped anucleated cells that have a diameter of 1 to $3 \mu \mathrm{m}$. A healthy individual possesses $150-350 \times 10^{9}$ platelets/L. In addition to their role in thrombosis and haemostasis, platelets participate in other pathophysiological processes including inflammation, atherogenesis, host defense, tumor growth and metastasis. Activated platelets have various mechanisms through which they can deliver signals to leukocytes, endothelial cells and other target cells. The best known is the rapid secretion of soluble mediators (for example von Willebrand factor, CXCL4 (PF4), CCL5 (RANTES)) with endocrine-paracrine signaling activity [9-11].

When platelets are activated in pathological situations they may contribute to the breakdown of the endothelial barrier, leading to fluid leakage and oedema formation. Aggregate of activated platelets and each of the major classes of leukocytes have been reported in clinical samples and/or inflammatory models [12-14]. It is believed that the pathogenesis of malaria-induced thrombocytopaenia is multifactorial and involves bone marrow suppression, antibody-mediated platelet destruction, platelet phagocytosis, adhesion to activated endothelium and interactions with parasitized erythrocytes and leukocytes leading to sequestration of these aggregates and oxidative stress generated during parasite growth [15-17].
Pathogen-associated molecular patterns (PAMPs), including glycosylphosphatidylinositol (GPI) [18] and haemozoin [19] may mediate pathologic events triggered by plasmodial parasites. In addition, haem may be a key molecular agonist in malaria. During malaria infection haemoglobin is used as a source of nutrient for replication by the Plasmodium sp. Digestion of haemoglobin leads to haem release. Several studies point to haem as capable of generating inflammation similar to malarial infection [20]. Free haem accumulates on the plasma of children with cerebral malaria triggered by $P$. falciparum, suggesting that it may have a pathological effect on human malaria [21]. Free haem is metabolized by haem oxygenase-1 (HO-1) leading to the release of three byproducts, equimolarly, the free iron ion $\left(\mathrm{Fe}^{2+}\right)$, carbon monoxide (CO) and biliverdine [22]. The role of HO-1 enzyme has already been studied in experimental cerebral malaria models [23] and in the pathogenesis of nonencephalic forms of severe malaria [24]. Pena et al. and Pereira et al. described a protective effect for HO-1 in malaria-induced lung injury $[25,26]$.

Pulmonary malaria in patients develops before, during or after initiation of treatment [27], when release of molecular patterns associated with the parasites and derived from tissue damage occurs, leading to increased expression of haem oxygenase [6]. Platelets have a undefined role in the pathophisioloy of malaria [28, 29]. But in recent years, studies showed that inhibition of platelets activation correlates with decreased pulmonary vascular permeability due malaria infection [30, 31]. Also, it has already been observed that the increase in $\mathrm{HO}-1$ expression correlates with decreased platelet activation and adhesiveness $[32,33]$. Therefore, the hypothesis of this work that the modulation of haem oxygenase activity alters thrombocytopaenia and lung injury during infection with Plasmodium berghei strain NK65.

\section{Methods \\ Mouse models of malaria}

Wild Type C57BL/6 weighing 20-25 g was obtained from the Oswaldo Cruz Foundation breeding unit and used throughout the study. All animals used in this work were male and six to eigth weeks old. The animals were kept at constant temperature $\left(25^{\circ} \mathrm{C}\right)$ with free access to food and water in a room with a 12-h light/dark cycle. Plasmodium berghei strain NK65 was kindly provided by Dr. Juliana Tavares (UFMG). Mice were infected intraperitoneally (i.p.) by injection of $200 \mu \mathrm{L}$ of $1 \times$ phosphate buffered saline (PBS) with $10^{4}$ parasitized red blood cells (pRBC [34]) or, as control group, $10^{4}$ red blood cell (RBC). Parasitaemia was measured from the count of parasitized and non-parasitized red blood cells in a total of 100 cells. This count was repeated in five independent fields and the 
average of the percentage of parasitized red blood cells performed. All analyses were performed at day 7-10 post-infection. Between 90 and 100\% of infected mice developed lung injury.

\section{Ethics statement}

The Animal Welfare Committee of the Oswaldo Cruz Institute approved the experiments in these studies under license number P-0528-08 and L025/15. The procedures described in this study were in accordance with the local guidelines and guidelines published in the National Institutes of Health Guide for the Care and Use of Laboratory Animals. The study is reported in accordance with the ARRIVE guidelines for reporting experiments involving animals.

\section{Treatment}

For each experiment, a new solution of Cobalto Protoporphyrin IX/CoPPIX (PORPHIRIN-Logan, Utah) at a concentration of $5 \mathrm{mg} / \mathrm{kg}$ was prepared. The CoPPIX is used as an inducer of the haem oxigenase-1 enzyme [23]. The drugs were diluted in $0.9 \%$ sodium chloride/sterile saline (HEMAFARMA) solution containing 0.5\% DMSO (Sigma). The solutions were sonicated (2510-BRANSON) for $20 \mathrm{~min}$, and $200 \mu \mathrm{l}$ was administered intraperitoneally for 8 days, starting at the day after infection. Saline solution with $0.5 \%$ DMSO (sigma) was administered (i.p.) as a group control. Infected and non-infected animals were evaluated for parasitaemia and survival until 15 days after the infection.

\section{Bronchoalveolar lavage fluid (BALF)}

The animals were submitted to euthanasia by inhalation of isoflurane and bronchoalveolar lavage (BAL) samples were collected. After euthanasia, the trachea and section of adjacent muscles were exposed. Thereafter, a small hole was opened in the prominent region of the tracheal cartilage for insertion of a cannula attached to a $21 G$ (BD) needle. Bronchoalveolar lavage fluid (BALF) was obtained by injecting $1 \mathrm{~mL}$ of ice-cold PBS, followed by aspiration of the contents, and this procedure was repeated 3 times. At the end of the process, an approximate volume of $0.9 \mathrm{~mL}$ of BALF per mouse was recovered. BALF was used for total and differential leukocyte count and for protein measurement. Total leukocytes (diluted in Turk's 2\% acetic acid fluid) were counted using Neubauer chamber haemocytometer. Differential counts were performed in cytospins (Cytospin3, Shandon, CA, USA) stained by the May-Grünwald-Giemsa method. The BALF was spun at $350 \mathrm{~g}$ at room temperature for $5 \mathrm{~min}$, and the supernatant was removed and stored at $-80{ }^{\circ} \mathrm{C}$ for further analyses. BALF total protein concentration was measured using a BCA protein assay kit (Thermo Scientific, Waltham, MA, USA).

\section{Cytokine determinations}

Perfused lungs from infected and uninfected mice were excised and homogenized in $750 \mathrm{~mL}$ of a protease inhibitor cocktail (Complete, mini EDTA-free Roche Applied Science, Mannheim, Germany) for $30 \mathrm{~s}$, using a UltraTurrax Disperser T-10 basic (IKA-Guangzhou, China). Homogenates were stored at $-20{ }^{\circ} \mathrm{C}$, for analysis of cytokines using a commercial ELISA kit according to the manufacturer's instructions (R\&D Systems Duo set kits, Minneapolis, USA).

\section{Lung permeability}

The lung permeability was determined by intravenous injection of Evans blue dye (Sigma-Aldrich Brasil LTDA, São Paulo, Brazil) 2\% (w/v) solution in phosphate-buffered saline (PBS). One hour later the animals were sacrificed with terminal anesthesia by isoflurane and the vasculature was intracardiacaly perfused with $20 \mathrm{~mL}$ phosphate-buffered saline (PBS) using a peristaltic pump system. The lungs were collected and placed in $2 \mathrm{~mL}$ of formamide (VETEC Química Fina LTDA, Duque de Caxias, RJ, Brazil) at $37{ }^{\circ} \mathrm{C}$, overnight to extract Evans blue dye from the tissue. Absorbance was measured at $\lambda=620 \mathrm{~nm}$ (Molecular Devices Spectra Max 190, Sunnyvalle, CA, USA). Evans blue dye concentration was calculated from a standard curve and was expressed as mg of Evans blue dye per lung tissue.

\section{Lung histology}

Perfused lungs from infected and uninfected mice were inflated by injecting $1.0 \mathrm{~mL}$ of $10 \%$ buffered formalin through the same catheter used to perform BALF. Lungs were removed fixed in formalin and embedded in paraffin. Lungs sections of $5-\mu \mathrm{m}$ thickness were stained with haematoxylin-eosin. Analysis of tissue sections was performed in an Olympus BX41 microscope (Melville, NY, USA) at a magnification of $200 \times$. The number of mononuclear cells in lung tissue was determined by the pointcounting technique across 20 random, non-coincidents microscopic fields in an Olympus BX41 microscope at a magnification of $1000 \times$.

\section{Platelet count}

A small amount of peripheral blood $(2 \mu \mathrm{L})$ was obtained from the tail vein. The blood was immediately transferred to a solution containing $47 \mu \mathrm{L}$ of buffered HT solution (10 mM Hepes, $137 \mathrm{mM} \mathrm{NaCl}, 2.8 \mathrm{mM} \mathrm{KCl}, 1 \mathrm{mM} \mathrm{MgCl}$ 2, $12 \mathrm{mM} \mathrm{NaHCO}$ 3, $0.4 \mathrm{mM} \mathrm{Na} 2 \mathrm{HPO}$ 4, bovine serum albumin (Citric acid $8 \mathrm{~g} / \mathrm{L}$, sodium citrate $22.4 \mathrm{~g} / \mathrm{L}$, glucose $2 \mathrm{~g} / \mathrm{L}$, sodium citrate; $\mathrm{pH}$ 5.1) and $0.5 \mu \mathrm{l}$ of APC 
fluorophore anti-CD41a antibody (clone eBioMWReg30 eBioscience), followed by incubation for $30 \mathrm{~min}$. After incubation, $250 \mu \mathrm{l}$ of the lysis solution (FACS lysing-BD) was added, and incubated for another $10 \mathrm{~min}$ at room temperature, and then stored $4{ }^{\circ} \mathrm{C}$. To perform platelet counts $40 \mu \mathrm{L}$ of beads (SPHEROTM AccuCount Particles-Spherotech, Inc.) with known size and $40 \mu \mathrm{L}$ of blood were used. The beads are larger than the platelets and do not present fluorescence, thus allowing the identification and quantification of the platelets. The acquisition was performed using the flow cytometer (FacsCalibur, BD), and analysed using the Cell Quest (BD) software.

\section{Measurement of platelet-leukocyte aggregate formation}

One hundred $\mu \mathrm{L}$ of peripheral blood was obtained by cardiac puncture using a $21 \mathrm{G}$ needle containing $20 \mu \mathrm{L}$ of an anticoagulant solution composed of PSG buffer $(5 \mathrm{mM}$ PIPES, $145 \mathrm{mM} \mathrm{NaCl}$, glucose $5.5 \mathrm{mM}$ (Hepamaxs-Blau) and $0.5 \mathrm{mM}$ prostaglandin E1 (PGE1, Cayman Chemical). Platelets were labelled with $0.5 \mu \mathrm{L}$ of APC fluorophore labelled anti-CD41a (clone: eBioMWReg30 eBioscience); monocytes with $0.8 \mu \mathrm{L}$ of labelled anti-CD14 antibody (clone: rmC5-3 BD Bioscience) with PE fluorophore, red cells with $0.8 \mu \mathrm{L}$ of labelled anti-TER119 antibody (clone:TER-119 Biolegend) with PE fluorophore, and neutrophils with anti- Ly6G (clone: 1A8 BD Bioscience) labelled with PE fluorophore and $0.6 \mu \mathrm{L}$ labelled antiCD11b (clone: M1/70 eBioscience) with PE-Cy7 fluorophore. The following control isotypes were used in this work: $0.5 \mu \mathrm{L}$ of mouse IgG1 anti-mouse (clone: eBRG1 eBioscience) APC, $0.8 \mu \mathrm{L}$ of IgG1 mouse anti-mouse PE (clone: RTK2758 BD Pharmingen), and $0.6 \mu \mathrm{L}$ of IgG2b mouse anti-mouse (clone: eB149/10HS eBioscience) PE-Cy ${ }^{\mathrm{TM}} 7$. The samples were incubated for $30 \mathrm{~min}$, protected from light. After incubation, $250 \mu \mathrm{l}$ of the lysing solution (FACS lysing-BD) was added, incubated for a further $10 \mathrm{~min}$ at room temperature, and storage in the refrigerator until read on the flow cytometer (FacsCalibur, BD). The analyses were performed using the Cell Quest (BD) program.

\section{Western blotting}

Macerated lungs (40 $\mu \mathrm{g}$ of total proteins) were diluted in Laemmli buffer. The proteins were then denatured by heating at $100^{\circ} \mathrm{C}$ for $10 \mathrm{~min}$ and then applied to the gel. Laemmli $4 \times$ buffer consisted of $1 \mathrm{M}$ Trizma Base (Sigma) solution $\mathrm{pH}$ 6.8, 8\% SDS, 40\% glycerol (Invitrogen), 20\% $\beta$-mercaptoethanol (Sigma), bromophenol blue (Sigma) and water Milli-Q. The samples were electrophoresed (12\% acrylamide gel) with the application of $125 \mathrm{~V}$ for one and a half hours and then transferred to nitrocellulose membrane (GE Healthcare). The transfer was performed at $100 \mathrm{~V}$ for $50 \mathrm{~min}$ in a wet system
(BioRad). After transfer, the membrane was incubated for $1 \mathrm{~h}$ with $5 \%$ milk blocking solution in TBS/T (addition of $0.05 \%$ Tween 20, Sigma). Subsequently, the membrane was washed with TBS/T and incubated overnight with rabbit monoclonal antibody against mouse anti-VCAM-1 (abcam), at 1:1000 dilution in 5\% skim milk in TBS/T. On the second day, the membrane was washed three times for $5 \mathrm{~min}$ with TBS/T and incubated for one and a half hours with anti-peroxidase-conjugated rabbit anti-IgG antibody (Vector) diluted 10,000-fold. The membrane was then washed three times for 5 min with TBS without Tween ${ }^{\circledR}$ and immersed in a solution composed of equal parts of SuperSignal West Pico Stable Peroxide Solution (Pierce) and SuperSignal West Peak Luminol/Enhancer Solution (Pierce) for $20 \mathrm{~min}$. After this time, excess solution was removed and the membrane was enclosed in a cassette containing a photosensitive film (Kodak) for development.

The loading control was done by the detection of $\beta$-actin expression. The membranes were washed three times for $5 \mathrm{~min}$ with TBS/T, then incubated for $15 \mathrm{~min}$ in the stripping solution (Unisciense), then washed three more times for $5 \mathrm{~min}$ with TBS/T. The membranes were then blocked for $30 \mathrm{~min}$ and $\beta$-actin antibody primary rabbit anti-mouse (Sigma) was added for $30 \mathrm{~min}$ at room temperature on the shaker (Labline). After this period three washes were again performed for $5 \mathrm{~min}$ with TBS/T, followed by incubation for $30 \mathrm{~min}$ with goat anti-rabbit IgG coupled to fluorophore (IRDye 800-RD) diluted 20,000-fold and the development in the Odssey Clx unit (Uniscience).

\section{Statistics}

Statistical analysis was carried out using the GraphPad Prism software (San Diego, CA, USA). P values were calculated using an unpaired Ordinary one-way ANOVA test when results from more than two groups were analysed among each other. $\mathrm{P}$ values were generated using an unpaired T-test when result from only two groups were analysed. In addition, Shapiro-wilk normality test was performed. Results are expressed as mean \pm SEM (median (IQR)). The level of significance was set at $\mathrm{P} \leq 0.05$.

\section{Results}

\section{Plasmodium berghei infection induces platelet activation and thrombocytopaenia}

Van den Steen et al. [26] demonstrated the development of experimental malaria-associated lung injury, with a survival rate of around $10 \%$ after 12 days. Here, using the same model, it was observed that infected animals start dying on the ninth day of infection. The highest mortality was seen between 9 and 12 days after infection, with 


\begin{abstract}
(See figure on next page.)
Fig. 1 Plasmodium berghei strain NK65 infection induces pulmonary injury. C57B1/6 animals were inoculated i.p. with $10^{4}$ non-parasitized red blood cells (NP-RBC) or with $10^{4}$ parasitized red blood cells (PRBC). a Survival curve during 15 days. In a different set of experiments the animals were euthanized after 8 days. BALF was collected and the total and differential number of cells counted. The total cell count was performed on the Turk solution, and differential counts were performed in cytospin smears stained by Panótico. $\mathbf{b}$ Number of total cells Number of mononuclear cells. c Number of polymorphonuclear cells. $\mathbf{d}$ For evaluation of lung oedema and histological studies animals were euthanized 9 days after infection. e Total lung weight. Ratio between dry/wet weight. f Protein concentration in the BALF. $\mathbf{g}$ Histological analysis. $\mathbf{h}$ The sections were stained with haematoxylin and eosin. The patterns shown in the photos are representative of three experiments, each containing five animals. Magnification of $\times 10$. The bar on the lower right corner of the photomicrographs indicates $100 \mu \mathrm{m}$. BALF and lung tissues were also processed for ELISA. i CCL-2/ MCP-1, CCL-5/RANTES, both evaluated in lung tissue (left side graphic) and in BALF (right side graphic). j Parasitaemia during 12 days. Graphics are representative of three experiments, each line being the average of ten animals per experimental group; ${ }^{*} \mathrm{p} \leq 0.05$ when compared to uninfected controls. P values were generated using an unpaired T-test
\end{abstract}

a survival rate at the end of the observation period being $20 \%$ (Fig. 1a). Besides, an intense accumulation of leukocytes in the BALF on days eight and ten after infection (Fig. 1b-d) was observed. Differential leukocytes count showed that the predominant cell leukocyte accumulated was mononuclear cells (Fig. 1c), while the number of polymorphonuclear cells did not change significantly when compared to uninfected animals (Fig. 1d). Here using this animal model, also observed a significant increase of oedema formation (Fig. 1e-g), an intense inflammatory infiltrate in the pulmonary parenchyma (Fig. $1 \mathrm{~h}$ ) and the release of important chemokines in the pulmonary lysate (Fig. 1i) after 9 days post-nfection. Figure $1 \mathrm{j}$ observed the animals' parasitaemia curve over the days after infection. The analyses were carried out on the 9th day after the infection as it is the point at which the mortality of the animals begins.

Thrombocytopaenia is a frequent haematological manifestation in malaria, caused by both for $P$. vivax and $P$. falciparum [35]. To evaluate the occurence of thrombocytopaenia in during experimental malaria infection, peripheral blood was collected from infected and control animals for haematological analysis using flow cytometry analysis. Figure 2a shows that control animals exhibited a relatively equal number of platelets over the observation period. However, the platelet counts of infected animals significantly decreased on the ninth day of infection. This result indicates that this animal model reproduces characteristics of the human disease at least with regard to the occurrence of thrombocytopaenia.

One potential explanation for thrombocytopaenia in infected animals is formation of cellular aggregates. Flow cytometry was used to evaluate formation of plateletsmonocytes (Fig. 2b) and platelets-neutrophils (Fig. 2c) aggregates on the ninth day of infection. Results here presented have been demonstrated that $P$. berghei infection causes activation of platelets and subsequent formation heteroaggregates of platelets and leukocytes, contributing to the underestimation of the number of platelets in the peripheral count.
HO-1 activity protects animals from mortality by $P$. berghei infection without affecting parasitaemia

Modulation of the haem oxygenase-1 (HO-1) enzyme in experimental cerebral malaria [23] and pulmonary injury [26] was shown to increase survival. To further examine HO-1 in pulmonary malaria, protoporphyrin cobalt (CoPPIX) as an inducer of HO-1 activity in vivo was used [23]. The treatment started 1 day after infection and was administered daily at $5 \mathrm{mg} / \mathrm{kg}$ CoPPIX for 8 consecutive days. Treatment with CoPPIX leads to an increase in the expression of the HO-1 enzyme in uninfected animals and this increase becomes more significant once infection occurs (Fig. 3a). Saline-treated animals exhibited extensive mortality started 9 days post-infection (Fig. 3a). However, only $12 \%$ of the infected animals treated with CoPPIX died between the eleventh and twelfth day of infection (Fig. 3b). Importantly, CoPPIX treatment did not alter parasitaemia in the infected group (Fig. 3c). These results indicate that treatment with CoPPIX has a protective effect in experimental malaria, increasing survival by a mechanism that is independent from the control of parasite replication and is probably related to modulation of the host response to infection.

\section{Increased HO-1 activity prevents alveolar-capillary barrier disruption in infected animals}

To investigate whether COPPIX treatment influences host response, cell migration into the lungs was evaluated. CoPPIX treatment was associated with a significant reduction in leukocyte numbers in the BALF as compared to infected animals treated with vehicle (Fig. 4a). The reduction in leukocyte numbers was mainly in the numbers of mononuclear cells as demonstrated by differential cell counting (Fig. 4b). Similarly, histologic analysis revealed that treatment with CoPPIX decreased cell infiltration in the lung parenchyma (Fig. 4f) when compared to infected animals treated with saline (Fig. 4e). It was also observed that treatment with CoPPIX does not lead to any lung damage since there are no noticeable differences between the lungs of animals that are not infected 

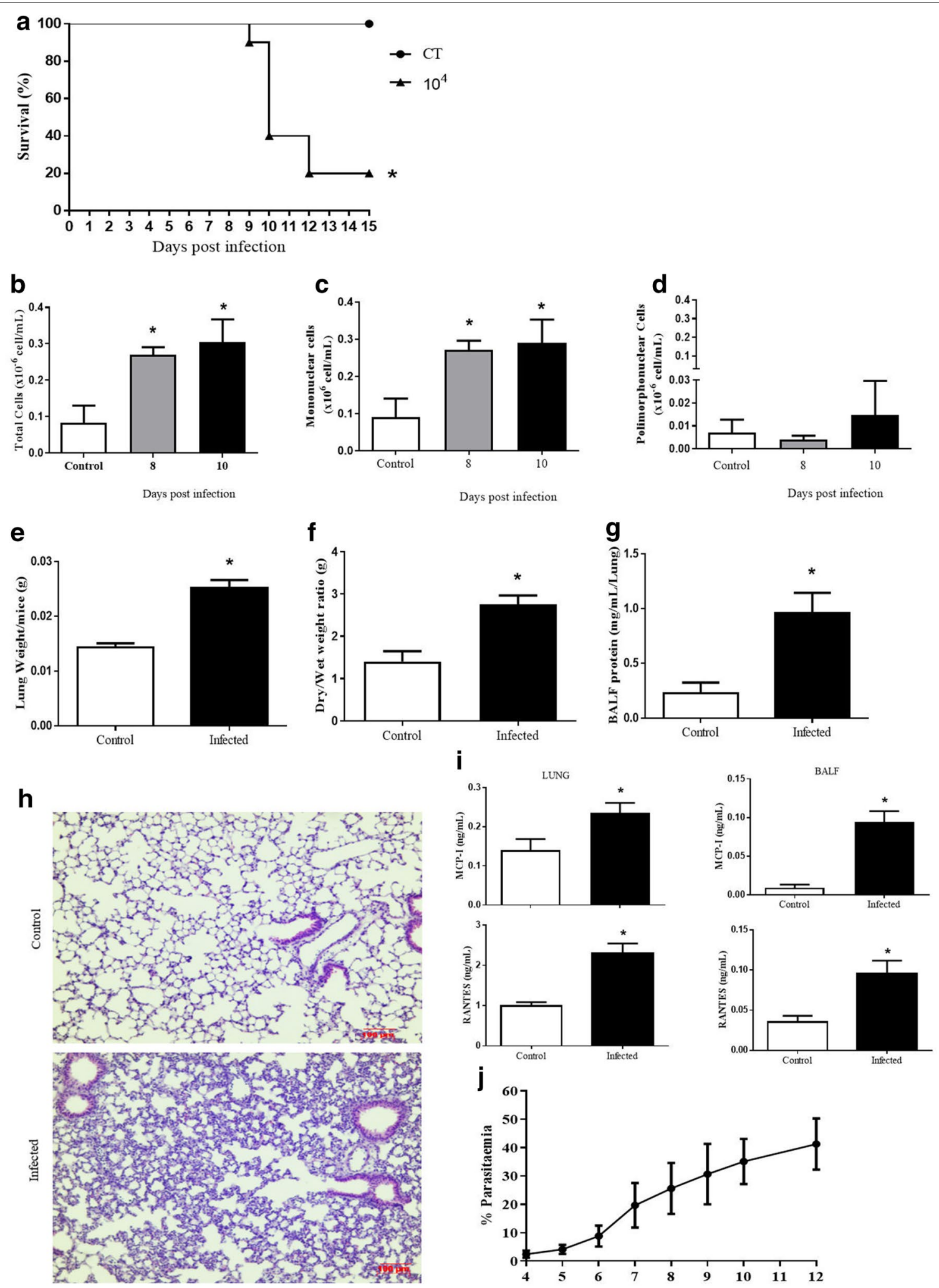


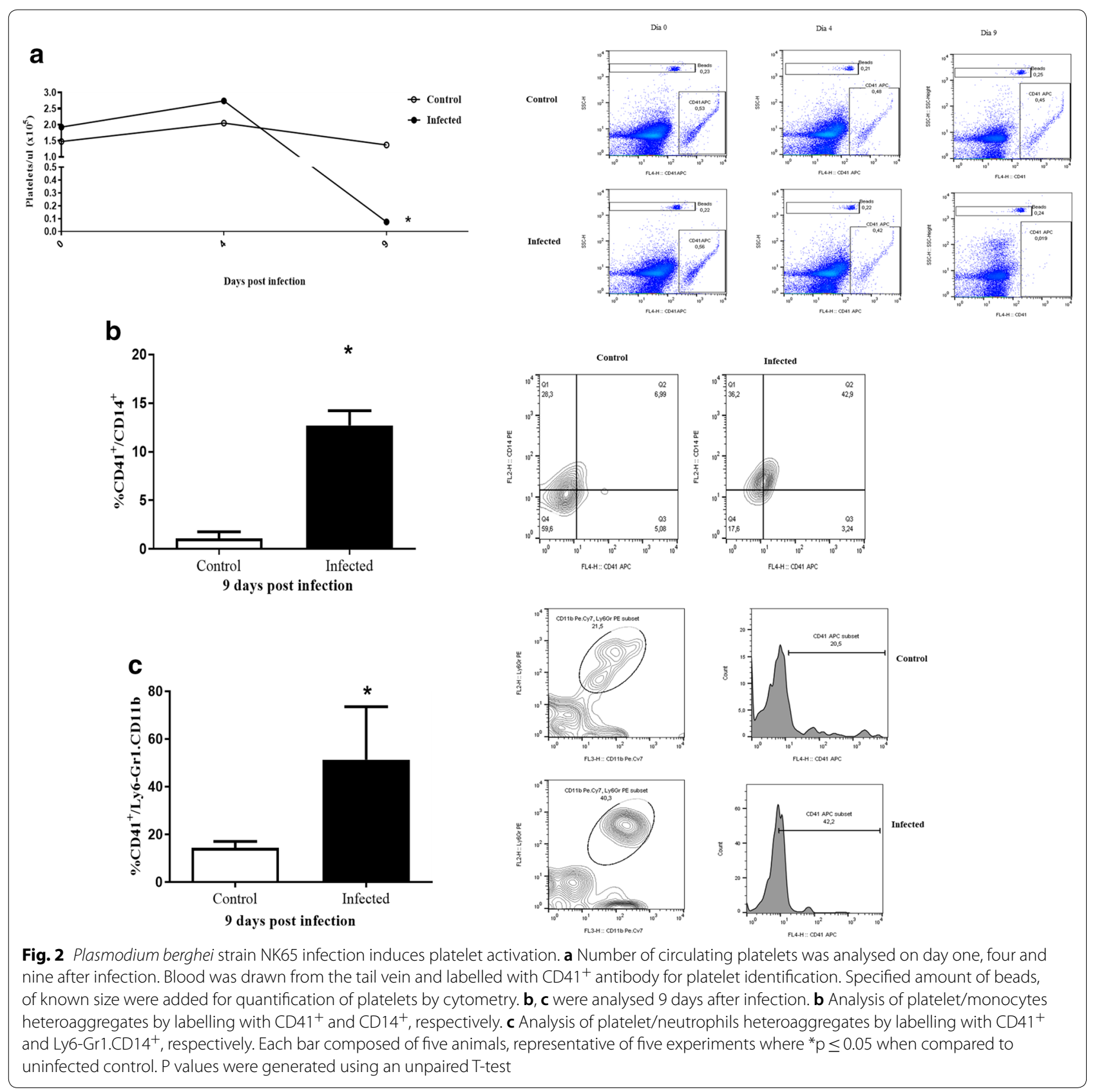

and treated with saline (Fig. 4c) or CoPPIX (Fig. 4d). Changes in the lung parenchyma of CoPPIX treated animals were also obvious by macroscopic examination. Lungs from CoPPIX treated animals showed a less intense dark coloration indicating a milder inflammation (Fig. 4f).

Infected animals had a significant extravasation of protein into BAL fluid relative to their uninfected controls (Fig. 1g). However, infected animals treated with CoPPIX showed significantly less extravasation compared to infected groups treated with saline indicating that treatment with CoPPIX protects against alveolar-capillary barrier dysruption. The Evans blue method was used to confirm disrupted alveolar-capilary barriers and that treatment with CoPPIX prevented this event (Fig. 4f).

\section{Increased HO-1 activity decreases the expression} of VCAM-1 but does not inhibit chemokine release

To further investigate the modulatory effect of HO-1 in lung inflammatory reaction of infected animals the 

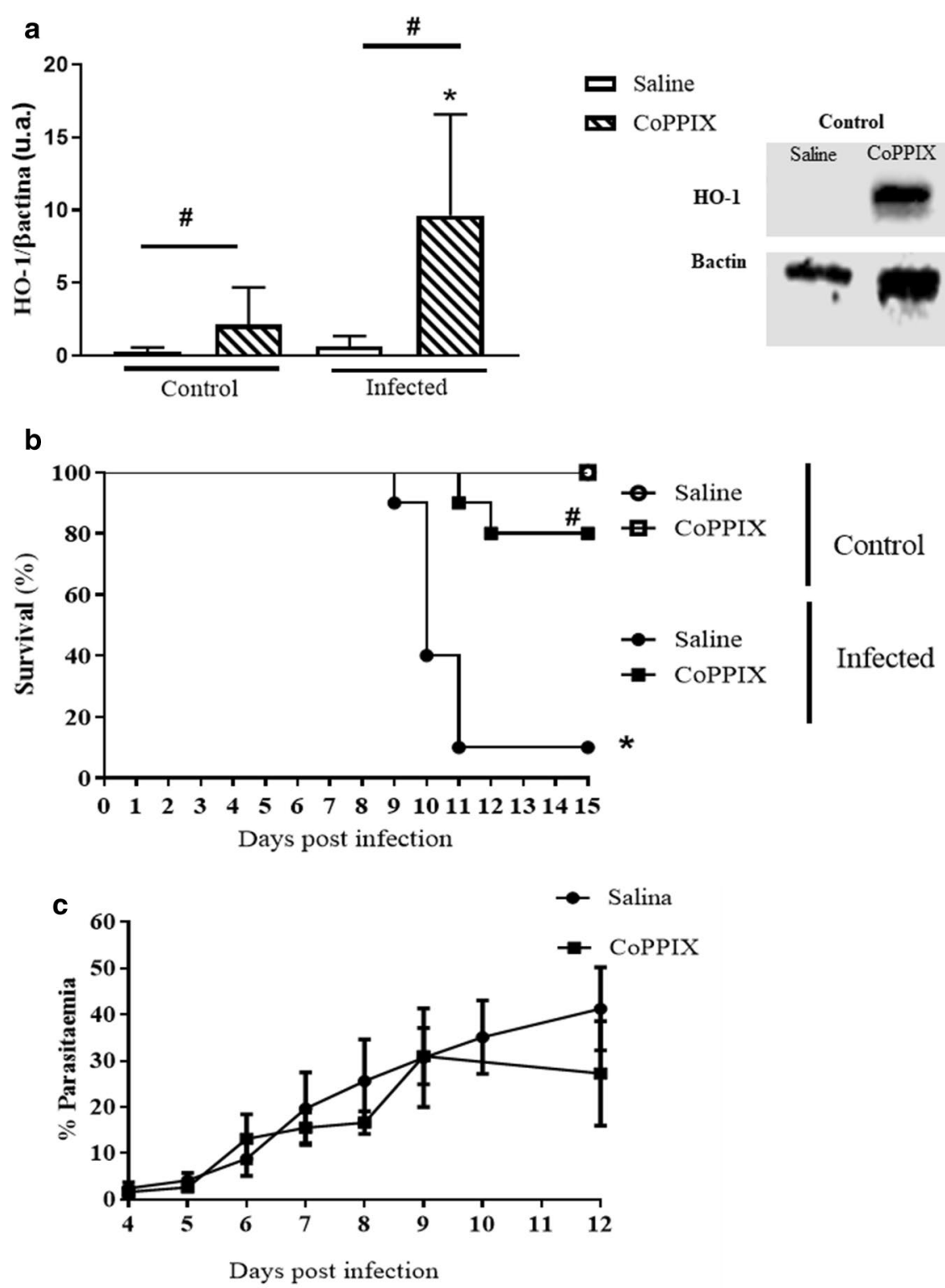

Fig. 3 Effect of CoPPIX on the development of malarial infection. Animals received daily i.p. injection of saline with 0.5\% DMSO (Saline) or 5 mg/kg of COPPIX (COPPIX). Blood smears were used to analyse the parasitaemia. a HO-1 expression increased after CoPPIX treatment, after 9 days infection. b Survival curve during 15 days. c Parasitaemia during 12 days, representative of three experiments, where ${ }^{*} p \leq 0.05$ when compared to infected animals in relation to uninfected controls, and (\#) indicates $p \leq 0.05$ infected animals treated with CoPPIX in relation to infected animals treated with saline. P values were calculated using an unpaired Ordinary one-way ANOVA test

\section{(See figure on next page.)}

Fig. 4 Treatment with CoPPIX decreases lung pathology. Animals received daily i.p. injection of saline with 0.5\% DMSO (Saline), or 5 mg/kg CoPPIX (CoPPIX) and were euthanized 9 days after infection. a Total leukocyte counts. b, c represent differential leukocyte counts. Mononuclear cells (b) and polymorphonuclear cells (c). Each bar composed of five animals. $\mathbf{d}-\mathbf{g}$. Macroscopic aspect of lungs and photomicrographs from control and infected animals treated or not with CoPPIX. Photos are representative of five animals per experimental group, and three independent experiments. Magnification of $\times 10$. The bar on the lower right corner of the photomicrographs indicates $100 \mu \mathrm{m}$. In H, protein content in the BALF. In I, Evans blue extravasation to the lung tissue (with macroscopic photos of the lungs representative of each group). Each bar averaging to 8-10 animals. The experiments were repeated 3 times with similar results. ${ }^{*} p \leq 0.05$ when compared to uninfected controls, and (\#) indicates $p \leq 0.05$ when compared to animals treated with COPPIX. P values were calculated using an unpaired Ordinary one-way ANOVA test 


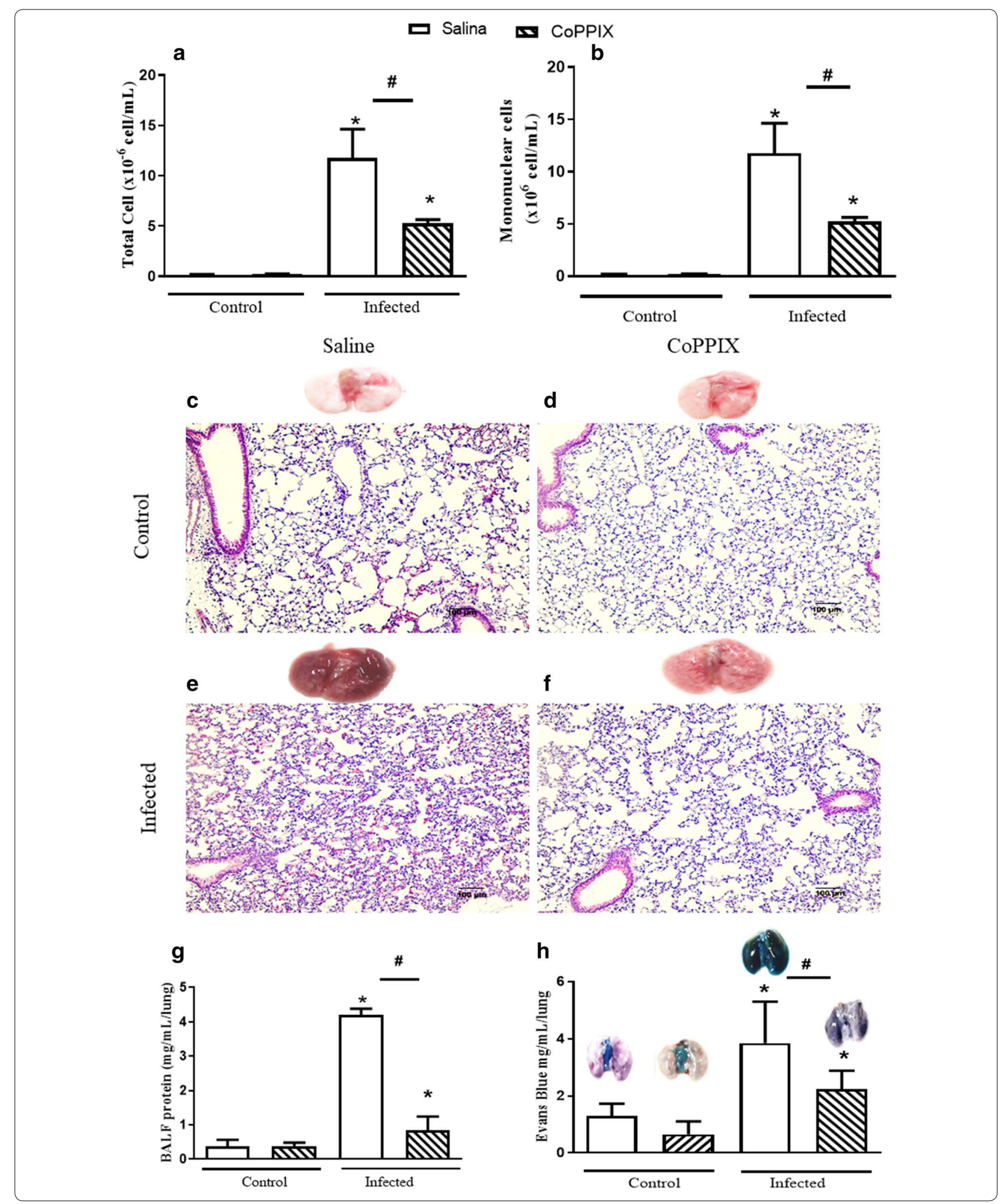


release of chemokines in the lung tissue, BALF and plasma 9 days after infection were measured. As expected, a significant increase in CCL-2/MCP-I (Fig. 5a top panel) and CCL-5/RANTES levels (Fig. 5a bottom panel) in all the analysed sites were observed. Surprisingly, treatment with CoPPIX did not interfere with the release of these chemokines in any of the compartments analysed.

Because endothelial activation influences cell migration and is also modulated by the activation of HO-1 [36], used lung lysates to evaluate the expression of VCAM-1 western blot. The infected animals treated with CoPPIX showed significantly less VCAM-1 expression than infected groups treated with vehicle (Fig. 5b). This indicated lesser activation of the endothelial cells, a potential explanation for lesser inflammation found in the treated animals.

\section{Increased HO-1 activity prevents platelets activation and thrombocytopaenia induced by $P$. berghei}

Control animals maintained a relatively constant platelet count throughout the experiment (Fig. 6a). As described above infected animals showed a decrease in the number of platelets by day six post-infection (Fig. 6a). Conversely, infected animals treated with CoPPIX did not developed thrombocytopaenia at any time during the experiment (Fig. 6a).

Infected animals showed increased formation of platelet-monocyte (Fig. 6b) and platelet-neutrophil (Fig. 6c) aggregates, demonstrating platelet activation [13]. Platelet factor 4 (PF-4), a platelet-derived CXC chemokine, was also increased in these animals (Fig. 6d), further suggesting platelet activation. On the other hand, infected animals treated with CoPPIX did not show significant increases in platelet heteroaggregates or PF-4 levels (Fig. 6b-d), indicating that HO-1 influences platelet activation and formation of aggregates of platelets and leukocytes in experimental malaria.

\section{Discussion}

Pulmonary injury characteristically occurs after initiation of anti-malarial treatment and is considered a complication linked to the exacerbated inflammatory response [3]. Malaria-induced acute lung injury presents with alveolar-capillary inflammation, altered lung ventilation/ perfusion relationships and gas exchange, variable airway obstruction, and increased pulmonary phagocytic activity [4]. In human and experimental malaria, metabolic changes, alteration of cytokine expression and sequestration of cells in the microcirculation of the brain and other organs are commonly seen $[2,37,38]$. One of the most important steps in the infectious process is the immunoinflammatory response that involves, among other events, the migration of cells and accumulation into the tissue. In this context, platelets are cells that have received much attention as new inflammatory roles have recently been described [11,39]. However, their role and activities in malaria have been controversial at best. Previous studies showed that platelet depletion or inhibition of aggregation in infection with $P$. berghei strain ANKA leads to a longer survival, suggesting that role platelet the formation of cerebral or lung injury due malaria [30, 40]. Also, in experimental cerebral malaria, a lower incidence of cerebral malaria was observed when P-selectin deficient mice were used [41]. Regarding lung injury triggered by infection with $P$. berghei strain NK65, it has also been noted that von Willebrand factor (VWF-a glycoprotein synthesized in endothelial cells and megakaryocytes, what is crucial in normal haemostasis and thromboinflammation), contributed to increased alveolar leakage and VWF deficiency was associated with elevated parasite load, anaemia, and shortened survival time [31]. Here a possible relationship between platelet activation, pulmonary injury and thrombocytopaenia due to infection by P. berghei NK65 and examined the influence of haem oxygenase in platelet activation and acute pulmonary injury during $P$. berghe $i$ infection was investigated.

Thrombocytopaenia is a common complication in both vivax and falciparum malaria, but its causes are still not fully elucidated $[35,42]$. Thrombocytopaenia in malaria seems to be correlated with platelet activation [35, 43]. The thrombocytopaenia was detected on the sixth day post-infection and that it correlated with the formation of heteroaggregates of platelet and leukocytes. Platelet adhesion to the endothelium or thrombopoiesis as contributors to thrombocytopaenia could not be excluded. Platelet responses are also altered in other infections syndromes. For example, platelet activation and aggregation are correlated with increased severity of human and experimental sepsis [44, 45], clinical and experimental studies shown that infection by Streptococcus induces platelet activation and increased adhesiveness that correlates to a worsening of the inflammatory picture [46].

Formation of heteroagregates of platelets and leukocytes, mainly monocytes, is a relevant pathophysiologic event in diseases such as diabetes [47], dengue [48], HIV infection [49], cardiovascular diseases [50] and in cancer [51]. Activation of platelets leads to increased adhesion to and activation of leukocytes, triggering the production and/or release of cytokines and chemokines. In fact, heteroaggregates of platelets and neutrophils were reported as deleterious in several models of pulmonary inflammation. In acid-induced lung injury heteroaggregates of platelets and neutrophils are frequently formed, and blockade of P-selectin leads to an improvement in the inflammatory response [14]. Also, neutrophil-dependent 


$$
\text { a }
$$

LUNG
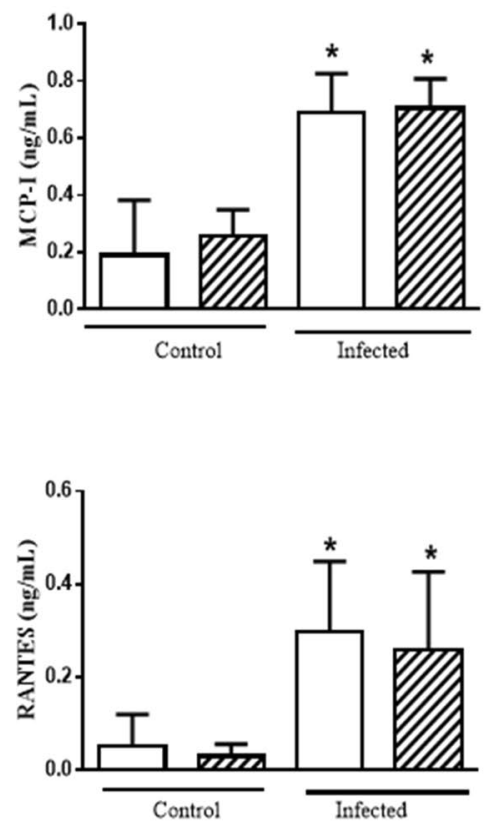

BALF
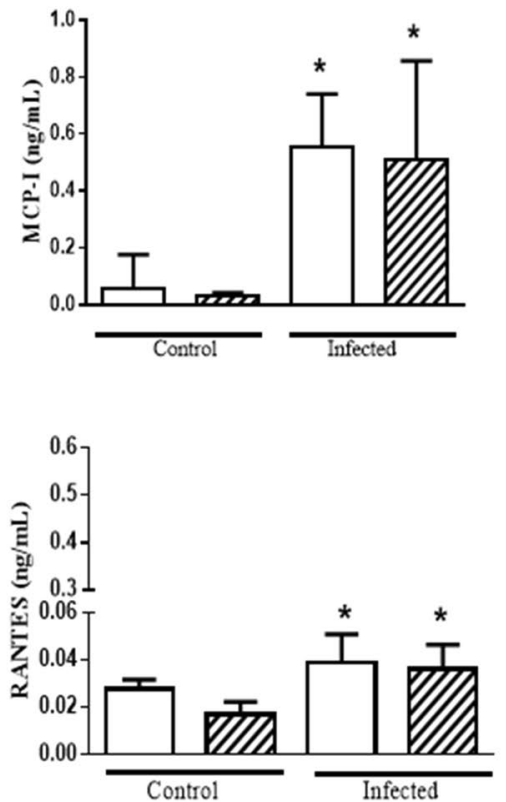

Control

b

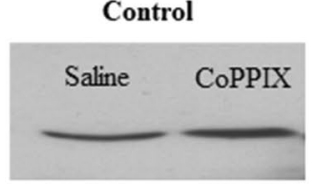

VCAM-1

Bactin

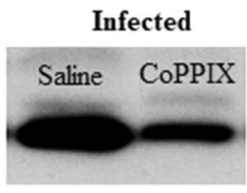

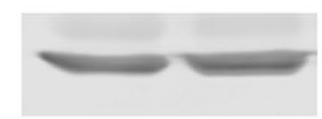
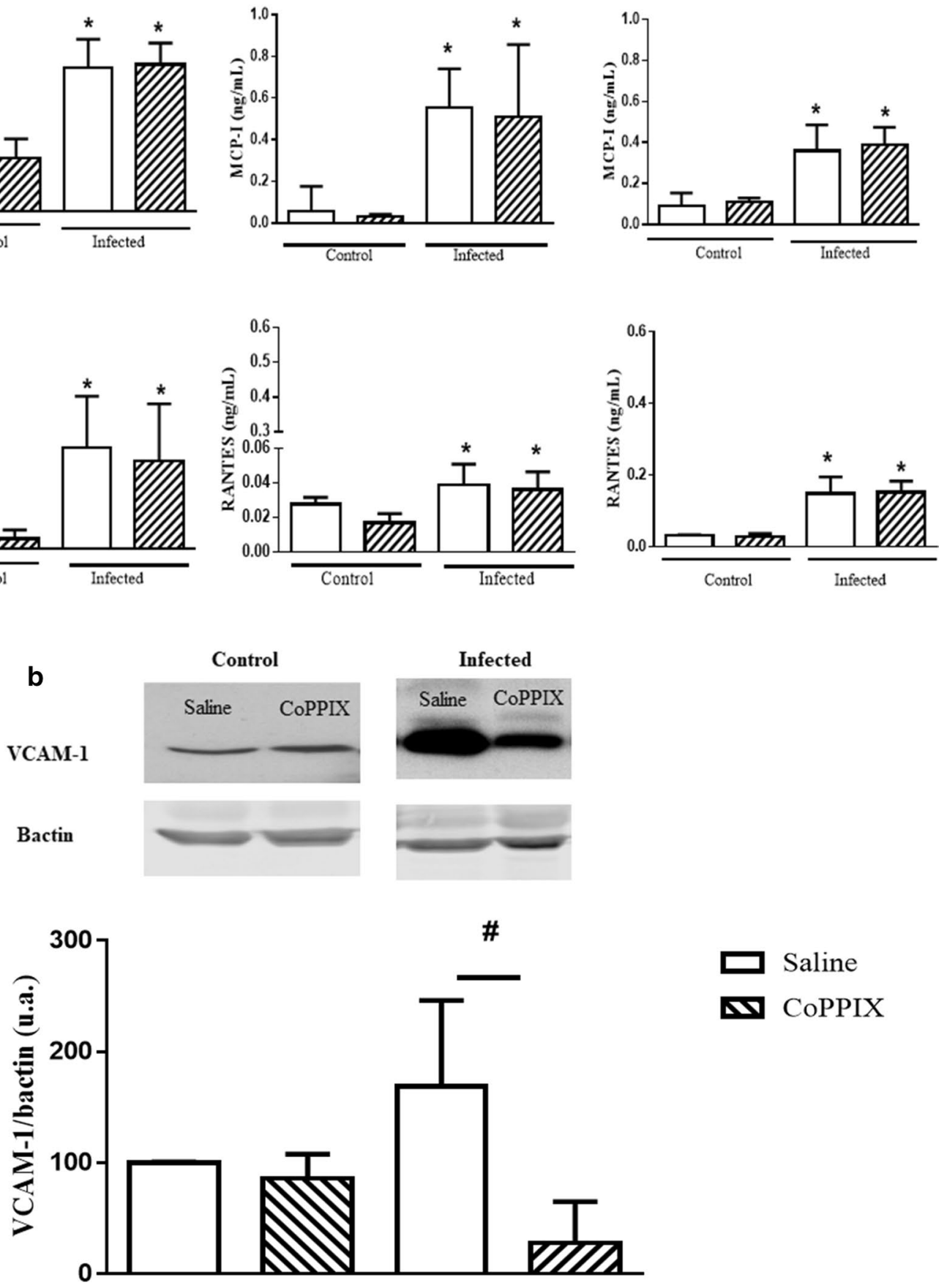

$\square$ Saline

$\mathbf{\nabla}$ CoPPIX

Fig. 5 Effect of COPPIX on chemokines release and expression of VCAM-1. Animals received daily i.p. injection of saline with 0.5\% DMSO (Saline) or $5 \mathrm{mg} / \mathrm{kg}$ CoPPIX (COPPIX) and were euthanized 9 days after infection. The lungs, BALF and peripheral blood were collected and processed for ELISA. A. CCL-2/MCP-1, and CCL-5/RANTES in lungs (left panels), BAL (middle panels) and plasma (right panels). Each is the mean from 5 animals. The experiment was repeated three times with similar results. ${ }^{*} \mathrm{p} \leq 0.05$ when compared to uninfected controls. $\mathbf{b}$ Lung samples from control and infected animals treated or not with CoPPIX were collected and used for analysis for VCAM-1 expression by western blot. $\beta$-bactin was used as normalizer (upper panel). Densitometry analysis is shown in the bottom panel. This is representative of five animals. (\#) indicates $p \leq 0.05$ when compared to CoPPIX treated animals. P values were calculated using an unpaired Ordinary one-way ANOVA test 
(See figure on next page.)

Fig. 6 CoPPIX treatment decreases platelet activation in P. berghei NK65 infected animals. C57B1/6 animals were inoculated i.p. with $10^{4}$ non-parasitized red blood cells (NP-RBC) or with $10^{4}$ parasitized red blood cells (PRBC). Animals received daily i.p. injection of saline with $0.5 \%$ DMSO (Saline) or $5 \mathrm{mg} / \mathrm{kg}$ CoPPIX (CoPPIX). Blood was collected from the tail vein at various times throughout the experiment. A. Platelet counts over a 7-day period. At day 7, cardiac puncture was performed and the blood was processed for cytometry. B. Analysis of the formation of platelet/ monocytes heteroaggregates, by labelling platelets with CD41a ${ }^{+}$and monocytes with CD14. C. Analysis of the formation of platelet/neutrophils heteroaggregates by labelling platelets with CD41a ${ }^{+}$and neutrophils with Ly6-Gr1.CD $11 b^{+}$. D. BALF was collected processed for PF4 detection by ELISA. Each bar is the mean from 5 animals. ${ }^{*} p \leq 0.05$ when compared to uninfected controls, and (\#) indicates $p \leq 0.05$ when compared to CoPPIX treated animals. P values were calculated using an unpaired Ordinary one-way ANOVA test

sequestration of platelets in the lung was identified in the transfusion-related lung injury (TRALI) model [52]. Worth mentioning the formation of platelet-induced neutrophil extracellular traps (NET) in the lung of animals with TRALI has also been described [53]. Data here presented suggest that similar events of platelet-mediated leukocyte activation may be present in P. berghei infection, contributing to a poor prognosis.

Malaria infection is accompanied by an intense release of haem after rupture of parasitized red blood cells. The presence of free haem during pathologic conditions triggers the induction of the enzyme haem oxygenase- 1 (HO1 ), which catalyzes haem releasing carbon monoxide and biliverdin, both potent antioxidant agents that may aid in the control of tissue damage. It was observed that treatment with CoPPIX did not interfere with the development of infection, however, CoPPIX treatment led to a significant increase in survival. Induction of HO-1 activity, in most cases by CoPPIX treatment, is associated to a protective effect in different pathologic conditions such as cardiac transplant rejection [54], and abortion after infection by Brucella abortus [55].

In experimental cerebral malaria induced by infection with $P$. berghei strain ANKA statin treatment has been shown to increase expression of the HO-1 and survival rate [56]. Similarly, CoPPIX treatment also increased survival in P. berghei ANKA infection [23], while haem, an important inducer of $\mathrm{HO}-1$, decreased mortality in a model of pulmonary malaria induced by $P$. berghei NK65 in DBA/2 animals [26]. Once no alterations were observed in the development of parasitaemia after CoPPIX treatment it can be possible that the protective effect of CoPPIX is a consequence of the control of the inflammatory response. In fact, CoPPIX treatment decreased oedema and accumulation of cells in the BAL and the lung parenchyma. Similar findings were reported in an influenza A virus model of infection where administration of haem (as HO-1 inducer) decreased lung oedema and cell accumulation into the lung parenchyma [57].

Although CoPPIX inhibited oedema and cell accumulation in experimental model here developed it did not interfere with the release of CCL-2/MCP-1 and CCL-5/RANTES. In contrast, the role of HO-1 in the malaria-associated lung injury model was evaluated in P. berghei ANKA-infected DBA/2 mice. Decreased accumulation of cytokines IFN- $\gamma$, IL-10 and CCL-2/MCP-1 in the lung and serum were found [26]. These results are in contrast with ours, but it is important to note that the authors used a different strain of Plasmodium and a different mouse background. Furthermore, they looked at cytokine expression by cytometry while detected the released protein by ELISA. However additional work analyzing a wider range of cytokines and examining both RNA and protein expression is necessary to gain a more definitive picture about cytokine modulation by $\mathrm{HO}-1$ in malaria ARDS.

Despite the lack of effect of CoPPIX on cytokine release, activation of endothelial was significantly affected as indicated by the decrease in the expression of VCAM-1 in CoPPIX-treated animals. This corroborates with the inhibition of oedema and cell accumulation, events associated with endothelial cell activation, and suggests that increased expression of HO-1 has cytoprotective and anti-inflammatory effects reducing activation of endothelial cells and consequently the expression of adhesion molecules, cell migration and oedema. This effect of HO-1 is not restricted to malaria and positive regulation of HO-1 decreases the expression of adhesion molecules, such as P-selectin and E-selectin, and leukocyte adhesion in a model of endotoxic shock [58].

Interestingly, a case study of a HMOX1-deficient patient demonstrated that the absence of the enzyme triggered endothelial damage, high plasma levels of von Willebrand factor, increased ICAM-1 expression, coagulation and fibrinolysis defects, generalized inflammation and premature atherosclerosis. The patient died at 6 years old suffering from growth retardation, anaemia, leukocytosis, thrombocytosis, coagulation abnormality, elevated serum levels of haptoglobin, ferritin and haem, a low serum bilirubin concentration and hyperlipidaemia. Autopsy revealed the presence of amyloid deposits, foamy macrophages, fatty streaks and fibrous plaques [59]. This case of HO-1 deficiency is an example that confirms the importance of $\mathrm{HO}$ expression in homeostasis and its involvement with activation of endothelial cells and the expression of adhesion molecules. 

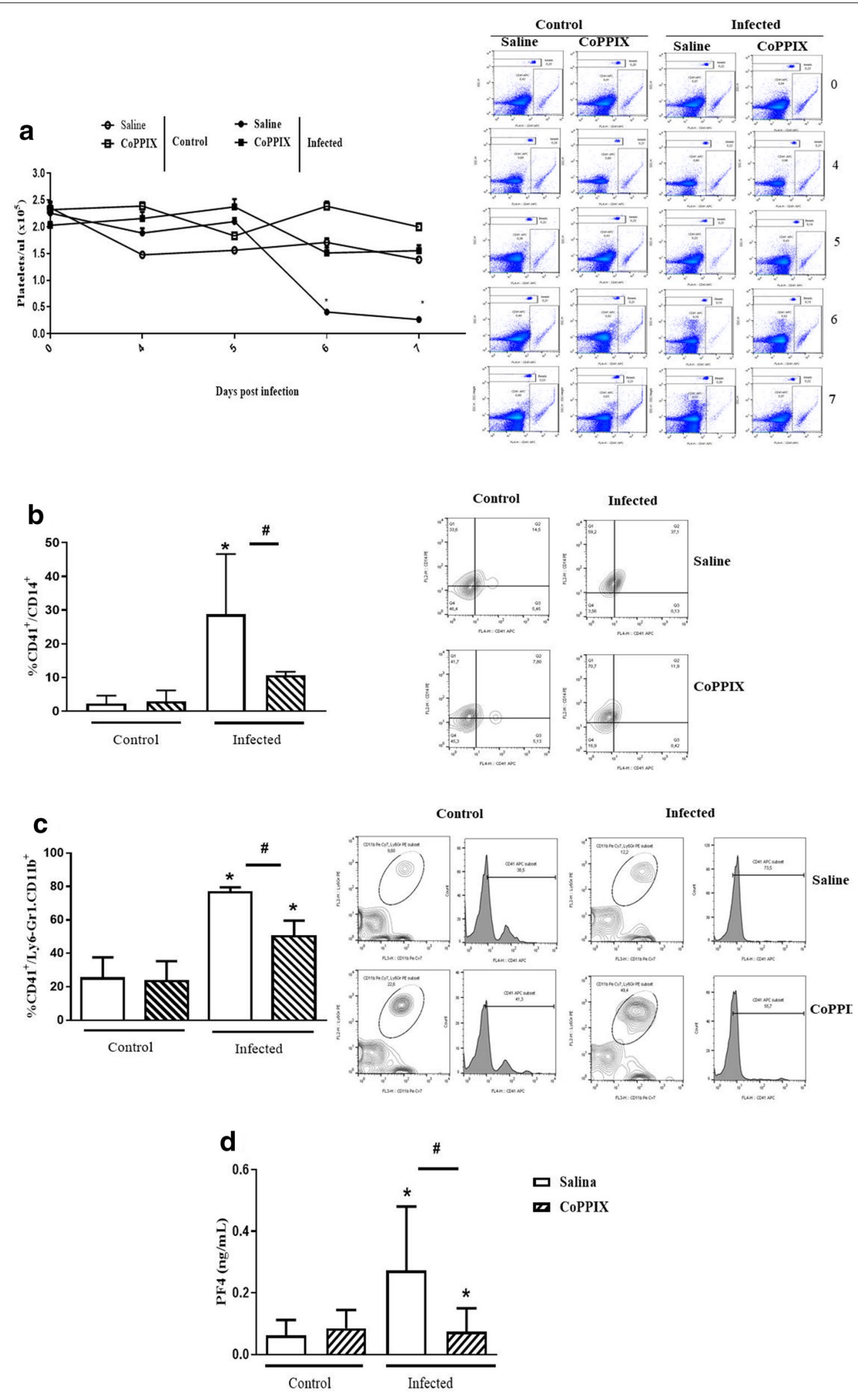
When analysing the role of HO-1 in thrombocytopaenia, it was observed that infected animals treated with CoPPIX did not show a decreased in peripheral platelet counts. In addition, platelet activation was inhibited as demonstrated by a significant decrease in formation of platelet/leukocytes heteroaggregates. It is documented in the literature that the HO- 1 enzyme plays an important role in inhibiting platelet activation and aggregation under stress conditions [33], in cardiovascular diseases [32] and in hepatic injury caused by ischemia and reperfusion events [60]. In the present work, reduced platelet activation was confirmed by quantifying the release of an important platelet-derived immunoregulatory mediator, PF4. Systemic treatment with COPPIX dramatically decreased the release of this chemokine into the BAL fluid, consistent with reduced platelet activation and inflammation. These data add to previous studies that inflammation ans accumulation leukocytes in experimental influenza infection and in other ALI models $[61,62]$.These studies indicate that the activation of the HO-1 enzyme leads to decreased platelet activation and adhesiveness that could influence the peripheral platelet count.

Taking together, data here presented suggest that that HO-1 modulation may have a beneficial role in the treatment of lung injury triggered by malaria. Nevertheless in a very elegant literature review about the role of haem oxygenase- 1 in experimental and human malaria, the authors made clear of the dual role of this enzyme, once in the asymptomatic phase (hepatic stage of the disease), HO-1 expression reduces inflammation and consequently provides a favorable environment for the development and multiplication of parasites. But in posterior stages of infection (blood stage), characterized by the accumulation of free haem and haemozoin as a result of parasitized erythrocyte burst and inflammatory response, HO-1 increase would be more beneficial as it would prevent the toxic effects of haem and reduce an exacerbated inflammation [63]. Since the liver stage can coexist with the blood stage in endemic areas where the rate of infection is high and an individual can be infected several times in a short period of time, understanding the HO-1 mechanisms at work during the different stages of infection by Plasmodium sp becomes of fundamental importance.

\section{Conclusion}

The study demonstrates that haem oxygenase- 1 is an important molecular effector that influences thrombocytopaenia and lung injury associated with malaria. CoPPIX treatment was able to decrease alveolar-capillary membrane "leak", alveolar monocyte and macrophage accumulation, and lung oedema, indicating that HO-1 is a key determinant of critical pathophysiologic events in this model of malaria associated lung injury. Thrombocytopaenia is another important aspect of the pathophysiology of malaria. Few studies have been conducted to understand what leads to this phenomenon. In conclusion, during experimental malaria infection, there was a dramatic platelet activation demonstrated by the formation of heteroaggregates of platelets and leukocytes and by the release of PF-4, and that treatment with CoPPIX decreases this activation. These data suggest that a better understanding of the role of haem oxygenase in the various infectious stages of malaria, may be an important tool in the treatment of lung injury and thrombocytopaenia associated with malaria.

\section{Abbreviations}

MA-ARDS: Malaria-associated acute respiratory distress syndrome; ARDS:

Acute respiratory distress syndrome; RBC: Red blood cell; pRBC: Parasitized red blood cell; BALF: Bronchoalveolar lavage fluid; PF4: Platelet-derived chemokine (C-X-C motif) ligand 4(CXCL4).

\section{Acknowledgements}

The authors are grateful to Dr. Juliana Tavares (UFMG) for kindly providing the P. berghei NK65 strain.

\section{Authors' contributions}

IGAQ designed and performed the experiments, discussed the results, analysed the data and wrote the manuscript. IMMM, ACF, PAR, AVA and RAC designed and performed the experiments, discussed the results and analysed the data. RAC and ASW discussed the results and analysed the data. IGAQ, AVA, GAZ and HCCFN conceived and designed the study, discussed the results and wrote the manuscript. PTB, PMRS and GAZ reviewed the manuscript. AVA, PTB, GAZ and HCCFN funded this work. All authors read and approved the final manuscript.

\section{Grant and funding information}

This work was supported by the Conselho de Desenvolvimento Científico e Tecnológico (CNPq), Fundação de Amparo a Pesquisa do Estado do Rio de Janeiro (FAPERJ), Programa de Núcleos de Excelência (Pronex) of the government of Brazil. Dr. Zimmerman's work was supported by the U.S. National Institutes of Health, the Margolis Foundation, and a CNPq Ciencia Sem Fronteiras Special Visiting Professorship.

\section{Availability of data and materials}

The data supporting the conclusions of this article are provided within the article and its additional files. The original datasets analysed in this current study are available from the corresponding author upon request.

\section{Ethics approval and consent to participate}

The Animal Welfare Committee of the Oswaldo Cruz Institute approved the experiments in these studies under the licence number no P-0528/08 e L025/15.

\section{Consent for publication}

Not applicable.

\section{Competing interests}

The authors declare that they have no competing interests.

\section{Author details}

${ }^{1}$ Laboratório de Imunofarmacologia, Instituto Oswaldo Cruz, Fundação Oswaldo Cruz, Rio de Janeiro, RJ, Brazil. ${ }^{2}$ Universidade Iguaçu, Nova Iguaçu, RJ, Brazil. ${ }^{3}$ Division of Endocrinology, Metabolism, and Diabetes, University 
of Utah School of Medicine, Salt Lake City, UT, USA. ${ }^{4}$ Department of Internal Medicine and Program in Molecular Medicine, University of Utah, Salt Lake City, UT, USA.

Received: 5 March 2020 Accepted: 20 June 2020

Published online: 01 July 2020

\section{References}

1. WHO. World Malaria Report 2019. Geneva, World Health Organization, 2019.

2. Schofield L, Grau GE. Immunological processes in malaria pathogenesis. Nat Rev Immunol. 2005;5:722-35.

3. Tan LK, Yacoub S, Scott S, Bhagani S, Jacobs M. Acute lung injury and other serious complications of Plasmodium vivax malaria. Lancet Infect Dis. 2008;8:449-54.

4. Anstey NM, Jacups SP, Cain T, Pearson T, Ziesing PJ, Fisher D, et al. Pulmonary manifestations of uncomplicated falciparum and vivax malaria: cough, small airways obstruction, impaired gas transfer, and increased pulmonary phagocytic activity. J Infect Dis. 2002;185:1326-34.

5. Sarkar S, Saha K, Das CS. Three cases of ARDS: an emerging complication of Plasmodium vivax malaria. Lung India. 2010;27:154-7.

6. Van den Steen PE, Deroost K, Deckers J, Van Herck E, Struyf S, Opdenakker $\mathrm{G}$. Pathogenesis of malaria-associated acute respiratory distress syndrome. Trends Parasitol. 2013;29:346-58.

7. Middleton EA, Rondina MT, Schwertz H, Zimmerman GA. Amicus or adversary revisited: platelets in acute lung injury and acute respiratory distress syndrome. Am J Respir Cell Mol Biol. 2018;59:18-35.

8. Gérardin P, Rogier C, Ka AS, Jouvencel P, Brousse V, Imbert P. Prognostic value of thrombocytopenia in African children with falciparum malaria. Am J Trop Med Hyg. 2002;66:686-91.

9. Gremmel T, Frelinger AL, Michelson AD. Platelet physiology. Semin Thromb Hemost. 2016;42:191-204.

10. Engelmann B, Massberg $\mathrm{S}$. Thrombosis as an intravascular effector of innate immunity. Nat Rev Immunol. 2013;13:34-45.

11. Vieira-De-Abreu A, Campbell RA, Weyrich AS, Zimmerman GA. Platelets: versatile effector cells in hemostasis, inflammation, and the immune continuum. Semin Immunopathol. 2012;34:5-30.

12. Goncalves R, Zhang X, Cohen H, Debrabant A, Mosser DM. Platelet activation attracts a subpopulation of effector monocytes to sites of Leishmania major infection. J Exp Med. 2011:208:1253-65.

13. Michelson AD, Barnard MR, Krueger LA, Robert Valeri A; C, Furman MI. Circulating monocyte-platelet aggregates are a more sensitive marker of in vivo platelet activation than platelet surface P-selectin studies in baboons, human coronary intervention, and human acute myocardial infarction. Circulation. 2001;104:1533-7.

14. Zarbock A, Singbartl K, Ley K. Complete reversal of acid-induced acute lung injury by blocking of platelet-neutrophil aggregation. J Clin Invest. 2006;116:3211-9.

15. Faille D, El-Assaad F, Alessi MC, Fusai T, Combes V, Grau GER. Plateletendothelial cell interactions in cerebral malaria: the end of a cordial understanding". Thromb Haemost. 2009:102:1093-102.

16. Seka-Seka J, Brouh Y, Yapo-Crézoit AC, Atseye NH. The role of serum immunoglobulin $\mathrm{E}$ in the pathogenesis of Plasmodium falciparum malaria in Ivorian Children. Scand J Immunol. 2004;59:228-30.

17. Coelho HCC, Lopes S, Pimentel JP, Nogueira PA, Costa FT, et al. Thrombocytopenia in Plasmodium vivax malaria is related to platelets phagocytosis. PLoS ONE. 2013:8:e0063410.

18. Mejia P, Diez-Silva M, Kamena F, Lu F, Fernandes SM, Seeberger PH, et al. Human C1-inhibitor suppresses malaria parasite invasion and cytoadhesion via binding to parasite glycosylphosphatidylinositol and host cell receptors. J Infect Dis. 2016;213:80-9.

19. Deroost K, Tyberghein A, Lays N, Noppen S, Schwarzer E, Vanstreels E, et al. Hemozoin induces lung inflammation and correlates with malariaassociated acute respiratory distress syndrome. Am J Respir Cell Mol Biol. 2013;48:589-600.

20. Wagener FA, Volk HD, Willis D, Abraham NG, Soares MP, Adema GJ, et al. Different faces of the heme-heme oxygenase system in inflammation. Pharmacol Rev. 2003;2003(55):551-71.
21. Sambo MR, Trovoada MJ, Benchimol C, Quinhentos V, Gonçalves L, Velosa $R$, et al. Transforming growth factor beta 2 and heme oxygenase 1 genes are risk factors for the cerebral malaria syndrome in Angolan children. PLoS ONE. 2010;5:e0011141

22. Li C, Stocker R. Heme oxygenase and iron: from bacteria to humans. Redox Rep. 2009;14:95-101

23. Pamplona A, Ferreira A, Balla J, Jeney V, Balla G, Epiphanio S, et al. Heme oxygenase-1 and carbon monoxide suppress the pathogenesis of experimental cerebral malaria. Nat Med. 2007:13:703-10.

24. Seixas E, Gozzelino R, Chora A, Ferreira A, Silva G, Larsen R, et al. Heme oxygenase-1 affords protection against noncerebral forms of severe malaria. Proc Natl Acad Sci USA. 2009:106:15837-42.

25. Pena AC, Penacho N, Mancio-Silva L, Neres R, Seixas JD, Fernandes AC, et al. A novel carbon monoxide-releasing molecule fully protects mice from severe malaria. Antimicrob Agents Chemother. 2012;56:1281-90.

26. Pereira MLM, Ortolan LS, Sercundes MK, Debone D, Murillo O, Lima FA, et al. Association of heme oxygenase 1 with lung protection in malariaassociated ALI/ARDS. Mediators Inflamm. 2016;2016:4158698.

27. Manicone AM, Huizar I, McGuire JK. Matrilysin (Matrix Metalloproteinase-7) regulates anti-inflammatory and antifibrotic pulmonary dendritic cells that express CD103 (aEß3-Integrin). Am J Pathol. 2009;175:2319-31.

28. Srivastava K, Cockburn IA, Swaim AM, Thompson LE, Tripathi A, Craig A, et al. Platelet factor 4 mediates inflammation in experimental cerebral malaria. Cell Host Microbe. 2008;4:179-87.

29. Wassmer SC, Moxon CA, Taylor T, Grau GE, Molyneux ME, Craig AG. Vascular endothelial cells cultured from patients with cerebral or uncomplicated malaria exhibit differential reactivity to TNF. Cell Microbiol. 2011;13:198-209

30. Darling TK, Schenk MP, Zhou CC, Maloba FM, Mimche PN, Gibbins JM, et al. Platelet a-granules contribute to organ-specific pathologies in a mouse model of severe malaria. Blood Adv. 2020:4:1-8.

31. Kraisin S, Verhenne S, Pham TT, Martinod K, Tersteeg C, Vandeputte N, et al. Von Willebrand factor in experimental malaria-associated acute respiratory distress syndrome. J Thromb Haemost. 2019;17:1372-83.

32. Li XL, Cao J, Fan L, Wang Q, Ye L, Cui CP, et al. Genetic polymorphisms of HO-1 and COX-1 are associated with aspirin resistance defined by light transmittance aggregation in Chinese Han patients. Clin Appl Thromb Hemost. 2013:19:513-21.

33. Peng L, Mundada L, Stomel JM, Liu JJ, Sun J, Yet SF, et al. Induction of heme oxygenase-1 expression inhibits platelet-dependent thrombosis. Antioxidants Redox Signal. 2004;6:729-35.

34. Van den Steen PE, Geurts N, Deroost K, van Aelst I, Verhenne S, Heremans $\mathrm{H}$, et al. Immunopathology and dexamethasone therapy in a new model for malaria-associated acute respiratory distress syndrome. Am J Respir Crit Care Med. 2010;2010(181):957-68.

35. Lacerda MV, Mourão MP, Coelho HCC, Santos JB. Thrombocytopenia in malaria: who cares? Mem Inst Oswaldo Cruz. 2011;106(Suppl 1):52-63.

36. Wagener FA, da Silva JL, Farley T, de Witte T, Kappas A, Abraham NG. Differential effects of heme oxygenase isoforms on heme mediation of endothelial intracellular adhesion molecule 1 expression. J Pharmacol Exp Ther. 1999:291:416-23.

37. Lacerda MV, Mourão MP, Alexandre MA, Siqueira AM, Magalhães BM, Martinez-Espinosa FE, et al. Understanding the clinical spectrum of complicated Plasmodium vivax malaria: a systematic review on the contributions of the Brazilian literature. Malar J. 2012;11:12.

38. de Azevedo-Quintanilha IG, Vieira-de-Abreu A, Ferreira AC, Nascimento DO, Campbell RA, Teixeira TP, et al. Integrin aDß2 (CD11d/CD18) mediates experimental malaria-associated acute respiratory distress syndrome (MA-ARDS). Malar J. 2016;15:393.

39. Weyrich AS, Zimmerman GA. Platelets: signaling cells in the immune continuum. Trends Immunol. 2004;25:489-95.

40. Van Der Heyde HC, Gramaglia I, Sun G, Woods C. Platelet depletion by anti-CD41 (alphallb) mAb injection early but not late in the course of disease protects against Plasmodium berghei pathogenesis by altering the levels of pathogenic cytokines. Blood. 2005;105:1956-63.

41. Sun G, Chang WL, Li J, Berney SM, Kimpel D, Van der Heyde HC. Inhibition of platelet adherence to brain microvasculature protects against severe Plasmodium berghei malaria. Infect Immun. 2003;71:6553-61.

42. Bakhubaira S. Hematological parameters in severe complicated Plasmodium falciparum malaria among adults in Aden. Turk J Haematol. 2013:30:394-9 
43. Sharron M, Hoptay CE, Wiles AA, Garvin LM, Geha M, Benton AS, et al. Platelets induce apoptosis during sepsis in a contact-dependent manner that is inhibited by GPIIb/IIla blockade. PLoS ONE. 2012;7:1-8

44. Gursel O, Atay AA, Kurekci AE, Avcu F, Nevruz O, Senses Z, et al. Platelet aggregation in children with Helicobacter pylori infection. Clin Appl Thromb Hemost. 2010;16637-42.

45. Lopes-Pires ME, Naime AC, Cardelli NJ, Anjos DJ, Antunes E, Marcondes S. PKC and AKT modulate CGMP/PKG signaling pathway on platelet aggregation in experimental sepsis. PLoS ONE. 2015;10:e0137901.

46. Svensson L, Frick IM, Shannon O. Group G streptococci mediate fibrinogen-dependent platelet aggregation leading to transient entrapment in platelet aggregates. Microbiology. 2016;2016(162):117-26.

47. Patkó Z, Császár A, Acsády G, Őry I, Takács É, Fűrész J. Elevation of monocyte-platelet aggregates is an early marker of type 2 diabetes. Interv. Med Appl Sci. 2012;4:181-5.

48. Hottz ED, Medeiros-de-Moraes IM, Vieira-de-Abreu A, de Assis EF, Valsde-Souza R, Castro-Faria-Neto HC, et al. Platelet activation and apoptosis modulate monocyte inflammatory responses in dengue. J Immunol. 2014;193:1864-72.

49. Singh MV, Davidson DC, Kiebala M, Maggirwar SB. Detection of circulating platelet-monocyte complexes in persons infected with human immunodeficiency virus type-1. J Virol Methods. 2012;2012(181):170-6.

50. Olsson A, Alfredsson J, Håkansson E, Svedjeholm R, Berglund J, Berg S. Protamine reduces whole blood platelet aggregation after cardiopulmonary bypass. Scand Cardiovasc J. 2016;50:58-63.

51. Chang YW, Hsieh PW, Chang YT, Lu MH, Huang TF, Chong KY, et al. Identification of a novel platelet antagonist that binds to CLEC-2 and suppresses podoplanin-induced platelet aggregation and cancer metastasis. Oncotarget. 2015;6:42733-48.

52. Looney MR, Nguyen JX, Hu Y, Van Ziffle JA, Lowell CA, Matthay MA. Platelet depletion and aspirin treatment protect mice in a two-event model of transfusion-related acute lung injury. J Clin Invest. 2009;119:3450-61.

53. Caudrillier A, Kessenbrock K, Gilliss BM, Nguyen JX, Marques MB, Monestier $M$, et al. Platelets induce neutrophil extracellular traps in transfusionrelated acute lung injury. J Clin Invest. 2012;122:2661-71.
54. Yamashita K, Ollinger R, McDaid J, Sakahama H, Wang H, Tyagi S, et al. Heme oxygenase- 1 is essential for and promotes tolerance to transplanted organs. FASEB J. 2006;20:776-8.

55. Tachibana M, Watanabe K, Yamasaki Y, Suzuki H, Watarai M. Expression of heme oxygenase- 1 is associated with abortion caused by Brucella abortus infection in pregnant mice. Microb Pathog. 2008;45:105-9.

56. Reis PA, Estato V, da Silva TI, d'Avila JC, Siqueira LD, Assis EF, et al. Statins decrease neuroinflammation and prevent cognitive impairment after cerebral malaria. PLoS Pathog. 2012;8:e1003099.

57. Wang C, Zhang Y, Han L, Guo L, Zhong H, Wang J. Hemin ameliorates influenza pneumonia by attenuating lung injury and regulating the immune response. Int J Antimicrob Agents. 2017;49:45-52.

58. Vachharajani TJ, Work J, Issekutz AC, Granger AD. Heme oxygenase modulates selectin expression in different regional vascular beds. Am J Physiol Heart Circ Physiol. 2000;278:H1613-7.

59. Kawashima A, Oda Y, Yachie A, Koizumi S, Nakanishi I. Heme oxygenase-1 deficiency: the first autopsy case. Hum Pathol. 2002;33:125-30.

60. Tamura T, Kondo T, Ogawa K, Fukunaga K, Ohkohchi N. Protective effect of heme oxygenase-1 on hepatic ischemia-reperfusion injury through inhibition of platelet adhesion to the sinusoids. J Gastroenterol Hepatol. 2013;28:700-6.

61. Grommes J, Alard JE, Drechsler M, Wantha S, Mörgelin M, Kuebler WM, et al. Disruption of platelet-derived chemokine heteromers prevents neutrophil extravasation in acute lung injury. Am J Respir Crit Care Med. 2012;185:628-36.

62. Guo L, Feng K, Wang YC, Mei JJ, Ning RT, Zhen HW, et al. Critical role of CXCL4 in the lung pathogenesis of influenza $(\mathrm{H} 1 \mathrm{~N} 1)$ respiratory infection. Mucosal Immunol. 2017;10:1529-41.

\section{Publisher's Note}

Springer Nature remains neutral with regard to jurisdictional claims in published maps and institutional affiliations.
Ready to submit your research? Choose BMC and benefit from:

- fast, convenient online submission

- thorough peer review by experienced researchers in your field

- rapid publication on acceptance

- support for research data, including large and complex data types

- gold Open Access which fosters wider collaboration and increased citations

- maximum visibility for your research: over $100 \mathrm{M}$ website views per year

At BMC, research is always in progress.

Learn more biomedcentral.com/submissions 